\title{
Free operant conditioning of the human eyelid response
}

DONALD A. SCHUMSKY, CHARLES L. RICHMAN AND JOHN TRIMDER

UNIVERSITY OF CINCINNATI

A yoked control double blind procedure was employed to demonstrate the free operant conditioning of the human eyelid response with reward. A high rate of conditioning was obtained for experimental Ss when compared to their initial operant level and/or the yoked controls. A statistically reliable conditioning effect was obtained even when the analysis included only those Ss unable to verbalize the response reward contingency relationship ("unaware $\mathrm{Ss}^{\text {") }}$.

Recent experimental attention has been focused on operant conditioning of the eyelid response with instrumental reward training (Fishbein, 1967; Fleming \& Grant, 1966; Hansche \& Grant, 1965). Each of these studies report successful instrumental eyelid conditioning employing problem solving instructions and recording S's responses with standard classical eyelid conditioning procedures. It is, therefore, of experimental interest to determine the nature of conditioning relationships when the eyelid response is being conditioned as a free operant. In short, it would be interesting to examine this type of conditioning in a situation where $\mathrm{S}$ did not have his eyelid directly connected to recording apparatus at the start of conditioning.

Keehn and his co-workers (Keehn, 1965; Keehn, Lloyd, Hibbs, \& Johnson, 1965) have demonstrated the possibility of conditioning the eyelid as a free operant. Yet, their experiments can only be considered exploratory in nature due to the small Ns employed (four Ss in each case), the fact that no control groups were employed, and no attempts were made to control such factors as experimenter bias.

The present experiment was designed to study the eyelid response conditioned as a free operant response employing reward training. A double blind procedure was employed so that $S$ did not know he was in a conditioning experiment nor did the $\mathrm{E}$ recording responses know whether he was recording responses for an experimental or control S. Finally, Ss were run in pairs to allow the employment of a yoked control procedure. Method

The Ss were 42 male undergraduate introductory psychology students who had volunteered to participate in the experiment in order to fulfill a course requirement.

Ss were admitted to the laboratory in pairs. Each $\mathrm{S}$ was seated on the side of a partition facing an E-recorder. The partition was sufficiently high so that each $S$ and his recorder could see each other but not the other $S$ and his recorder. An additional $E$ (E-reinforcer) sat in a screened enclosure behind both $E-$ recorders so that he could see both Ss. This third E had control of the administration of reward.
In front of each $S$, in a position such that it was screened off from the E-recorder's vision, was a reward light. Ss were instructed that they were in competition to gain points; they would not be told how to get points, but when they earned a point the light in front of them would light and their $\mathrm{E}$ would record a point. The reward lights were connected in parallel so that at any given session there could be one $\mathrm{S}$ whose reward light would be contingent upon his eyeblink and another $\mathrm{S}$ who would represent a yoked control, receiving a parallel series of non-eyeblink-contingent rewards. Only the E-reinforcer had pre-experimental access to the randomization determining which $S$ in a pair would be the experimental $S$. Thus, at least at the start of a session, the E-recorders did not know whether they were recording responses for an experimental or control $\mathrm{S}$.

The complete experimental session lasted $5 \mathrm{~min}$. There was an initial 1 min operant level period followed continuously by a 2 min conditioning period and a $1 \mathrm{~min}$ extinction period. Eyelid responses were counted over each $15 \mathrm{sec}$ throughout the experiment. Finally, a short questioning period was conducted to determine if Ss were able to verbalize the contingency relationship between the light and their eyelid response.

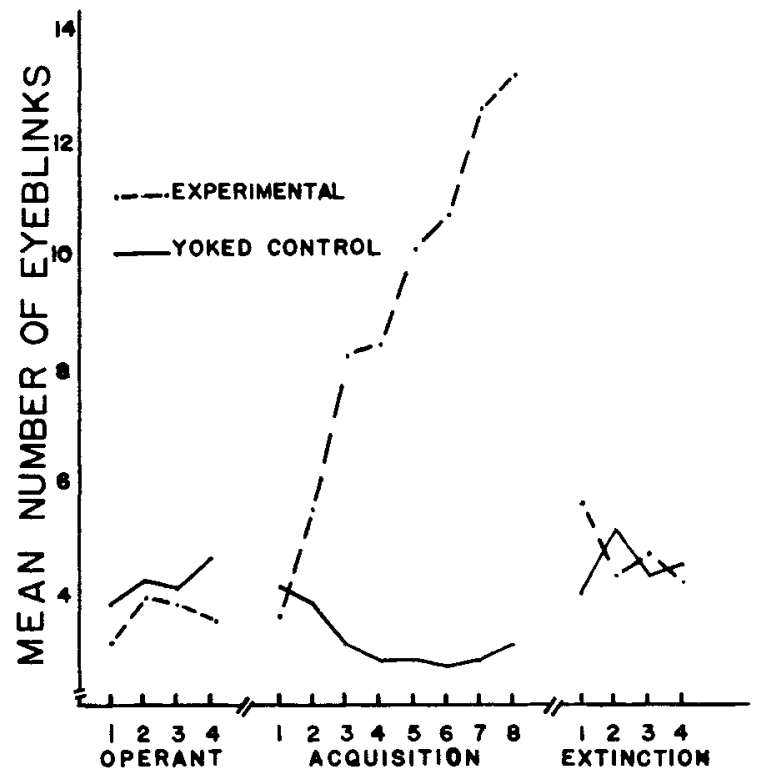

TRIAL PERIODS

Fig. 1. Mean number of eyeblinks for experimental (conditioning) Ss and their yoked controls plotted as a function of successive 15 sec trial periods through an initial operant period, acquisition and extinction. 


\section{Resulis}

The mean number of eyeblinks over each $15 \mathrm{sec}$ period throughout the experiment was computed for the 21 experimental Ss and their yoked controls. A plot of these means as a function of trial periods is presented in Fig. 1. As can be seen from the figure, the operant level for the yoked control Ss tended to be somewhat higher than that for the experimental Ss. This operant rate difference, though not statistically reliable $(t=0.73$, df $=40, n s)$, tended to make the great increase in eyeblink rate for the conditioning group appear even more dramatic. The correlation between mean operant eyeblink level and the amount of change during acquisition (Period 1 minus Perlod 8) for the 21 experimental Ss yielded $r=-.06$ (ns). There was a great increase in eyeblink rate over the elght $15 \mathrm{sec}$ trial periods of acquisition. Analysis of variance of responding during the acquisition period yielded statistically significant mean squares associated with the groups main effect $(F=10.98$, df $=1 / 40, p<.01$ ) and the groups by trial periods interaction mean square ( $F=8.82$, df $=7 / 280, p<.01$ ). A comparison of the mean number of eyeblinks in the last operant period with the mean of the last acquisition period for the experimental Ss showed these to be significantly different from one another $(t=2.82$, $d f=40$, $p<.01)$. The data from extinction reveal quite rapid extinction of the conditioned response. Analysis of the total extinction period yields no statistically significant difference between the control and experimental Ss. On the other hand, the experimental group shows a significantly higher mean eyeblink rate on the first $15 \mathrm{sec}$ trial of extinction $(t=1.80, \mathrm{df}=40, p<.05)$.

Quite fortuitous but nevertheless interesting is the uniform drop in eyeblink rate demonstrated by the control Ss concurrent with the administration of reward. This effect is apparently associated with the administration of reward as the initial operant level of response was recovered during extinction.

Post-experimental inquiry revealed that eight of the experimental Ss were able to verbalize the reward-eyeblink contingency established during the acquisition period. An examination of the conditioning data for only the 13 "non-aware" Ss and their yoked controls revealed an acquisition function with considerably less slope but which yielded significant differences over the acquisition period (groups by trials, $F=2.30, d f=7 / 158$, $p<.05)$. One yoked control $S$ reported awareness of a reward-eyelid response contingency relationship. In addition, a great amount of "superstitious" responding was noted in the behavior of both experimental and control Ss.

Discussion

The results of this experiment provide a strong demonstration of the ability to condition the eyelid re- sponse as a free operant in a reward training situation. The experimental Ss demonstrated great increases in eyeblink rate over their initial operant levels. In addition, their responding was significantly different from a yoked control group of Ss receiving a parallel but non-eyeblink-contingent set of rewards.

The yoked control Ss showed an interesting, albeit quite unexpected, tendency to reduce their eyeblink response rate over the acquisition trial series in which rewards were administered to them on a presumably non-response contingent basis. Keehn et al (1965) report that their Ss showed a decline in overall response rate when put on a DRL $4 \mathrm{sec}$ schedule. Perhaps the eyelid response of the control Ss came under the influence of reward in a similar fashion. On the other hand, the use of a visual reward signal, a brief flash of light, may have forced $S$ to reduce eyeblinks in order to maintain unhampered vigilance.

Ss who were able to verbalize the reward-response contingency relationship ("aware" Ss) were also the Ss generally showing the highest conditioning rates. It seems fruitless to get involved in controversy with regard to the unanswerable question of whether these Ss are aware because they conditioned so well or they conditioned so well because they are aware. Nevertheless these Ss showed great increases in eyeblink rate upon the administration of reward, as did the non-aware Ss. In addition, we find that they are able to verbalize a relationship that they did not know existed before the experiment. One might appropriately refer to this latter change in behavior as also demonstrating learning.

Finally, the present experiment provides a method for human operant conditioning employing a yoked control double blind procedure. This procedure gives promise of employment for conditioning studies involving a great number of possible responses. This would seem to be supported by the great amount of "superstitious" responding which developed with both experimental Ss and their yoked controls.

\section{References}

Fishbein, H. D. Effects of differential instructions, differential feedback, and UCS intensity on the conditioned eyelid response. J. exp. Psychol., 1967, in press.

Fleming, R. A., \& Grant, D. A. A comparison of rate and contingency of classical and instrumental reinforcement upon the acquisition and extinction of the human eyelid CR. J. exp. Psychol., 1966, 72, 488-491.

Hansche, W. J., \& Grant, D. A. A comparison of instrumental reward and avoidance training with classical reinforcement technique in conditioning the eyelid response. Psychon. Sci., $1965,2,305-306$.

Keehn, J. D. Differential eyelid conditioning of voluntary form responders. Psychon. Sci., 1965, 3, 583-584.

Keehn, J. D., Lloyd, K. E., Hibbs, M., \& Johnson, D. Operant eyeblink conditioning without awareness: A preliminary report. Psychon. Sci., 1965, 2, 357-358. 